\title{
Are GPs treating gonorrhoea appropriately?
}

Sean Perera1 ${ }^{1}$, Tamuka Gonah², Gillian Dean ${ }^{3}$

1.Brighton Health and Wellbeing Centre, Brighton, East Sussex BN3 1AE

2. Brighton Station Health Centre, Queens Road, Brighton, BN1 3XE

3.Brighton \& Hove Sexual Health \& Contraception (SHAC), Royal Sussex County Hospital, Eastern Road, Brighton, BN2 5BE

\section{INTRODUCTION}

- Gonorrhoea continues to develop progressive antimicrobial resistance

- Current recommended treatment for gonorrhoea is with dual therapy using a single dose of ceftriaxone $500 \mathrm{mg}$ intramuscularly, with azithromycin 1g orally

- GPs make an important contribution to gonorrhoea diagnoses with $\sim 4 \%$ of gonorrhoea cases diagnosed in primary care [2]

- Referral to specialist sexual health services for ongoing management is recommended for these cases [3]

- However recent data have shown $\sim 50 \%$ of cases are treated in primary care, with only $5-11 \%$ treated with first line antimicrobials

- Gonorrhoea rates are high (196/100,000 c.f. $70 / 100,000$ in England) in Brighton \& Hove, where there are 37 GP surgeries serving a population of 275,000 [4]

\section{AIMS}

- To document the proportion of gonorrhoea diagnosed in primary care in Brighton \& Hove (B\&H)

- To determine whether patients were advised to attend specialist clinics

- To record the management of gonorrhoea cases diagnosed in primary care

\section{METHODS}

- The Department of Microbiology at the Royal Sussex County Hospital provided a database of all cases of gonorrhoea diagnosed in Brighton \& Hove over a 2 year period (January 2015 to December 2016)

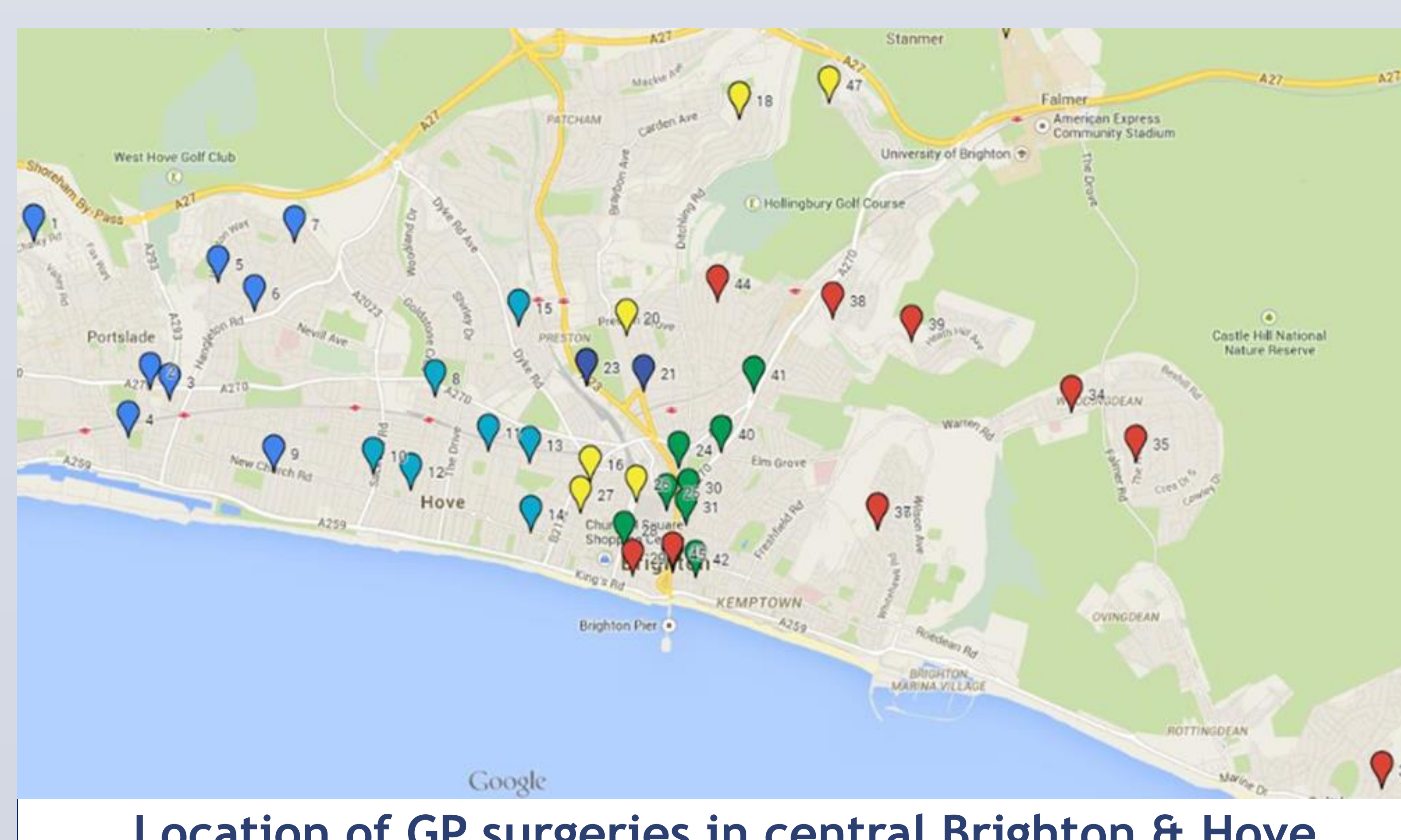

Location of GP surgeries in central Brighton \& Hove

- Cases diagnosed in primary care (37 practices) were identified

- The GPs managing these cases were contacted

- Management of the gonorrhoea and advice given to the patients at the time of diagnosis was obtained from the primary care records

\section{RESULTS}

- $1.7 \%(34 / 1,956)$ of all gonorrhoea cases in $\mathrm{B \& H}$ were diagnosed in primary care

- 18 male, 16 females; median age 32 (range 18-66 years)

- $88 \%(30 / 34)$ were already registered with B\&H Sexual Health Clinic (SHC)

- 56\% (19/34) attended the SHC for management (2 of these had prior treatment with azithromycin $1 \mathrm{~g}$, or azithromycin/ cefixime)

- The management of the remaining 15 patients is detailed below

\begin{tabular}{|c|c|c|}
\hline \multicolumn{3}{|c|}{ Treatment received in primary care } \\
\hline \multirow[t]{2}{*}{$1^{\text {st }}$ line therapy } & Treated in primary care & 3 \\
\hline & Referred and treated in level 2 service & 2 \\
\hline \multirow[t]{3}{*}{ Non-1 $1^{\text {st }}$ line therapy } & Oral cefixime $400 \mathrm{mg}$ + azithromycin $1 \mathrm{~g}$ stat & 2 \\
\hline & $\begin{array}{l}\text { Treated empirically at } 1^{\text {st }} \text { visit (azithromycin } 1 \mathrm{~g} \text { stat); } \\
\text { advised SHC but no record of attendance }\end{array}$ & 3 \\
\hline & $\begin{array}{l}\text { Treated empirically at } 1^{\text {st }} \text { visit (doxycycline } 100 \mathrm{mg} \text { bd } \\
1 \text { week); advised SHC but no record of attendance }\end{array}$ & 1 \\
\hline
\end{tabular}

Advised to attend level $2 / 3$ services but no record of attendance

No further information (surgery closed)

TOTAL

- $100 \%$ of patients not receiving 1 st line therapy had 'referral to SHC advised' documented in the notes

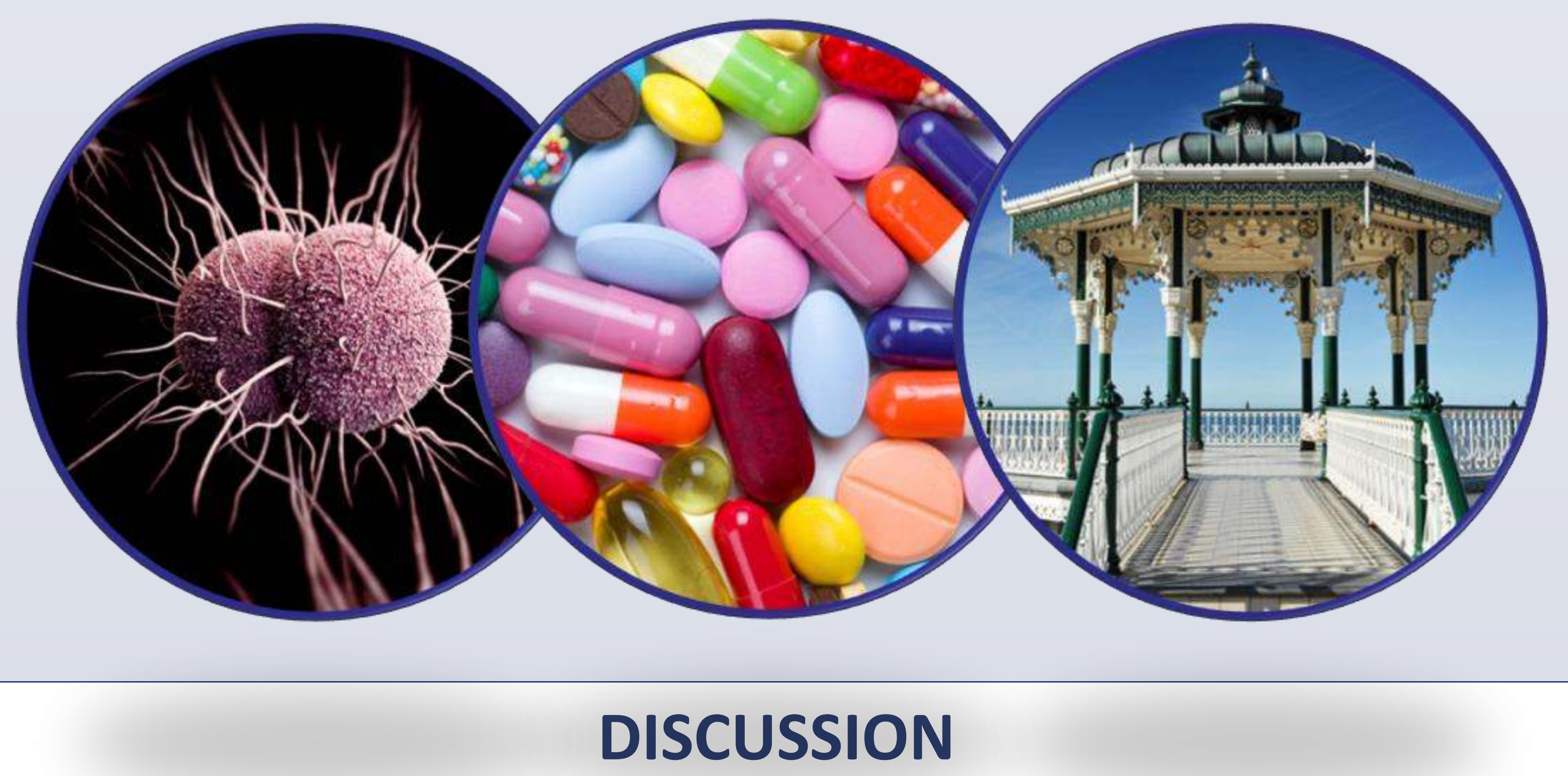

- Knowledge of correct gonorrhoea management pathways was high with all cases NOT receiving $1^{\text {st }}$ line therapy advised to attend specialist services

- Although oral cefixime/azithromycin is no longer recommended, cure can be achieved at an individual level

- It is likely some patients without 'record of attendance' visited other level 2/3 services outside our area

- The high number of female patients compared to our usual male to female ratio $(10: 1)$ raises doubts about false positive results in a low prevalence female population

\section{REFERENCES}

[1] BASHH Gonorrhoea treatment guidelines (2011)

[2] Mohammed $\mathrm{H}$, Sile B, Furegato $M$, Fifer $H$, Hughes $\mathrm{G}$. Poor adherence to gonorrhoea treatment guidelines in genera practice in England. Br J Gen Pract 2016; 66 (648): 352

[3] Standards for the management of sexually transmitted infections (STIs). Revised and updated January 2014. accessed $7^{\text {th }}$ June 2017 [4] Brighton \& Hove City Council, Census data (2011) 